\title{
La (re)construcción de la noción de ciudadanía por parte de los movimientos sociales en España
}

\section{Laura Guillén Olavide*}

\section{Resumen}

El propósito de este artículo es analizar el fundamento que tienen las demandas provenientes de los movimientos sociales españoles como la PAH y el 15M, sobre la base de la construcción de nuevas nociones del estatus de ciudadanía. Inmersos en el contexto de crisis económica, y como consecuencia de las políticas de austeridad impuestas desde la Unión Europea e implementadas a través del gobierno nacional, estos movimientos sociales ven el elemento social de la ciudadanía suprimido y abogan por un modelo ciudadano más próximo a la tradición propia del republicanismo.

\section{Palabras clave}

Movimientos sociales; ciudadanía; Unión Europea; crisis económica.

*Laura GUILLÉN OLAVIDE , Historiadora, máster en Análisis Político y aspirante al grado de Doctora en Ciencias Políticas por la Universidad Complutense de Madrid. Línea de investigación sobre Historia de las Ideas y Teoría Política.

\section{TITLE}

The (re)construction of the notion of citizenship developed by social movements in Spain

\begin{abstract}
The purpose of this article is to analize the foundation that the requests of the spanish social movements -such as PAH and 15M- have in the build of new ways of citizenship. Framed in the economic crisis context, and as a consequence of the austerity politics imposed by the European Union and displayed by the national government, these social movements perceive the social element of citizenship as deleted and advocate for a citizen model closer to the own tradition of the republicanism.
\end{abstract}

\section{KEYWORDS}

Social movements; citizenship; European Union; economic crisis. 


\section{1} - La adquisición de los derechos sociales de la ciudadanía.

T. H. Marshall se valía de la Historia para proponer en su célebre obra Ciudadanía y clase social una división de la condición de ciudadanía en tres partes. Tres elementos que, adquiridos de forma progresiva a lo largo del tiempo, terminaban por constituir el carácter pleno de la ciudadanía: por un lado el elemento civil, basado en libertades y derechos individuales -el de propiedad eminentemente-; el elemento político, entendido como el derecho a participar en el ejercicio del poder político; y finalmente, el social, que abarca "todo el espectro desde el derecho a la seguridad y a un mínimo bienestar económico, al de compartir plenamente la herencia social y vivir la vida de un ser civilizado conforme a los estándares predominantes en la sociedad"1.

Siguiendo al sociólogo, observamos cómo en otros tiempos fueron tres elementos que se entremezclaban, pero que con el avance histórico, se fueron diversificando y alejando entre sí, pasando a constituir componentes diferentes de un mismo concepto. Por ello Marshall nos decía que la evolución de la ciudadanía había implicado un doble proceso de fusión geográfica- y separación - funcional-22.

Desde este proceso de diferenciación que acontece con el paso de la antigüedad a la «modernidad», los derechos dejan de estar estrechamente ligados entre sí y pasan a ser objetivos a conquistar a través de las luchas sociales intergrupos. De este modo, el siglo XVIII será el siglo de la adquisición de los derechos civiles, que se pueden resumir en la igualdad ante la ley y en la garantía de las libertades individuales, como expresión, pensamiento, religión y, sobre todo, propiedad. En la siguiente centuria la lucha se centró en los derechos políticos, en un principio vinculados a estos derechos civiles, al desarrollarse en sociedades de economía capitalista, de modo que el derecho a la participación en el ejercicio político - tanto pasivo como activo- pasaba primero por la adquisición de los privilegios/derechos civiles de propiedad. No será hasta el siglo XX cuando se abandone dicha posición para empezar a considerar el derecho a la participación política como un elemento inherente al propio estatus del ciudadano, que además va a incluir una serie de derechos sociales, lo que se puede traducir -quizá de forma simplista- como el derecho al bienestar, independientemente de lo que ese "bienestar" puede significar en tanto en cuanto hablemos de libertades negativas o positivas.

Dejando a un lado este debate, que responde ya a corrientes distintas de teoría política y que, por consiguiente, desarrolla modelos de ciudadanía diferentes, cabe resaltar la adquisición por parte de la mayoría de los miembros de las sociedades occidentales de estos derechos sociales, fundamentalmente a partir de la construcción de lo que se ha convenido en denominar como los Estados del Bienestar o Welfare States.

El momento de creación de estos modelos sociales de Bienestar fue producto de una serie de procesos económicos y políticos, ambos originados a raíz de los acontecimientos

\footnotetext{
MARSHALL, Thomas Humprey, Ciudadanía y clase social, Alianza, Madrid, 1992 (1950), p. 23.

2 Fusión geográfica, puesto que se deja de concebir una ciudadanía de carácter local como ocurría en las antiguas polis griegas, para pasar a constituir, al llegar la «modernidad», un estatus puramente nacional. Por otro lado, separación funcional por el proceso de diferenciación de estos elementos constituyentes de la ciudadanía, que va de la mano de una diferenciación de las instituciones, antes amalgamadas. Íbidem, p. 25.
} 
derivados del fin de la Segunda Guerra Mundial y del clima de posguerra. En primer lugar, y al calor de la derrota de los ejércitos fascistas en los países de ocupación, se produjo la gestación de gobiernos de unidad nacional como coalición de fuerzas en los que participaron tanto partidos representantes de la socialdemocracia europea como los del centro-derecha y partidos bisagra más polarizados como los Partidos Comunistas de Francia e Italia. Estos "gobiernos de concentración" fueron capaces de crear un gran pacto social que dio como resultado este "Estado del Bienestar".

Por otro lado, cabe destacar la buena situación económica que se dio a partir del desarrollo de la doctrina keynesiana con políticas basadas en la fiscalidad y a la nacionalización de diversos sectores que habían dejado de ser rentables para la iniciativa privada, como el sector del carbón o los ferrocarriles británicos, pero que podían convertirse en un eje vertebrador de las economías estatales. A los propios efectos de esta nueva política económica se les unió el apoyo brindado por Estados Unidos y su Plan Marshall para la reconstrucción de las naciones implicadas en la guerra ${ }^{3}$, de modo que toda la situación económica propiciaba la generación de superávits que permitían destinar nuevos fondos a medidas de carácter social.

A partir de los años 50 se asiste a lo que se conoce como la "Edad de Oro del Capitalismo" ${ }^{4}$, en la cual se combinaron un periodo de energía - petróleo- y materias primas baratas, con lo que se redujeron notablemente los costes de producción; la socialización de los efectos del taylorismo y el fordismo de la Segunda Revolución Industrial -la extensión de la cadena de montaje y la producción masiva-; y finalmente, la existencia de unas herramientas financieras que acompañaban y facilitaban el desarrollo de este capitalismo del consumo de masas.

Se comenzó a gestar una sociedad basada en el consumo, de forma que para dar salida a toda la producción excedentaria consecuencia de la extensión de este modelo fordista se debía transformar la clase trabajadora en consumidora, generando nuevas necesidades mediante la publicidad y el marketing. El crecimiento económico creó la ilusión de una extensión de la clase media a la práctica totalidad de la población y se produjo un fenómeno de "individualización de la sociedad"5 al eliminar del imaginario de los individuos el factor común que les unía como grupo dentro de la sociedad de clases, cada vez más difuminada. Esta nueva y más numerosa clase media, hija natural del modelo de Bienestar basado en un Estado intervencionista, se nutrió de las mejoras de las condiciones laborales y materiales de los individuos, no sólo a raíz del aumento del salario directo, sino también de todos aquellos servicios que el estado proporcionaba a las personas de forma "gratuita" - por medio de sus

3 El Plan Marshall -o European Recovery Program como se llamó oficialmente- iniciado en 1948 respondía a la necesidad de Estados Unidos de asegurar la estabilidad económica en Europa para mejorar las condiciones sociales de los habitantes de estos países puesto que la pobreza era un factor que podía acercar a estos países al comunismo. Las autoridades económicas estadounidenses habían aprendido entre 1918 y 1939 y fundamentalmente durante la "Gran Depresión" el significado de su creciente liderazgo en la economía mundial, por lo que buscaban ahora evitar los errores que habían agravado su situación económica en el periodo entreguerras. Además, la economía norteamericana se encontraba en un alto grado de internacionalización, dado que como su capacidad de producción excedía con creces la demanda nacional interna, necesitaba una buena situación económico social en Europa que le permitiera dar salida para todos esos productos excedentarios. Por lo tanto, se daba la situación de que para mantener su propia sostenibilidad era preciso estabilizar también las economías europeas.

4 HOBSBAWN, Eric, Historia del siglo XX, Crítica, Barcelona, 2012 (1994).

5 BECK, Ulrich, La sociedad del riesgo global, Editorial Siglo XXI, Madrid, 1999. 
contribuciones impositivas-. Al mismo tiempo, el recién inaugurado Estado del Bienestar terminó por convertirse en uno de los pilares fundamentales que sustentaban el capitalismo de consumo de masas.

Todo ello, la conjunción de mejoras materiales y prestaciones sociales, o mejor dicho, el tener el derecho a las mismas, es lo que constituye básicamente el elemento social de la ciudadanía del que nos habla T.H. Marshall, y a él se refiere cuando habla del "derecho a la seguridad" - física, material y social-y de un "mínimo de bienestar económico", que garantice dicha seguridad. Para el sociólogo, la adquisición de estos derechos supone la consecución de la ciudadanía plena, puesto que hacía presuntamente efectiva la igualdad formal y material de los individuos. Por lo tanto, el desarrollo del Estado de Bienestar en Europa había supuesto la adquisición de los elementos propios de la condición de ciudadanía social que, sumados a los derechos ya obtenidos, constituían el carácter de ciudadanía más completo que había existido hasta la fecha. Al mismo tiempo, en el imaginario de los individuos que habían adquirido estos nuevos derechos sociales, el estatus de ciudadanía pasaba a reemplazar a su condición de clase ${ }^{6}$.

Al garantizarse a "todas las personas" 7 los derechos civiles, políticos y sociales, este Estado aseguraba que cada integrante de la sociedad se sintiera como un miembro pleno, capaz de participar y de disfrutar de la vida en común. Si se limitaba o violaba alguno de los derechos, se quedaba incapacitado para participar. A esta concepción se la conoce como «ciudadanía pasiva» o «ciudadanía privada» dando énfasis al carácter privado de los derechos y a la ausencia de responsabilidad o el deber de participar en la vida pública ${ }^{8}$, lo que la diferencia profundamente de nociones más próximas al republicanismo como las que desarrollan los movimientos sociales que aquí tratamos y que veremos más adelante.

\section{La destrucción de la ciudadanía social.}

Con las políticas de corte neoliberal iniciadas en la década de los ochenta y la crisis de 2008 hemos sido testigos de lo que ha significado la parcial desintegración del Estado de Bienestar y los elementos que componían el carácter de la "ciudadanía social". Gran parte de las políticas sociales que se habían realizado en el ciclo keynesiano partían de la idea de que los bienes públicos y los derechos sociales quedaban garantizados por la acción directa del estado; pero desde las últimas décadas del siglo XX se inicia un proceso de descapitalización de los Estados nación como tales, ya sea por medio del proyecto de integración europea que supone una cesión de soberanía a instancias supranacionales que no son plenamente democráticas ${ }^{9}$, como $^{2}$ por la expansión de la doctrina neoliberal en Europa desde los tiempos del "thatcherismo", que incluso extendió una mala consideración hacia los estados proveedores de beneficios sociales.

6 ESPING-ANDERSEN, Gøsta, Los tres mundos del Estado de Bienestar. Valencia: Alfons el Magnànim: Institució valenciana d'estudis i investigació, 1993.

7 Autoras pertenecientes a la tradición teórica del feminismo criticaban los postulados de Marshall por constituirse como una "falacia universalista", dado que sólo eran válidos para referirse al hombre blanco de clase media. Nancy Fraser y Linda Gordon, "Contract versus Charity: Why Is There No Social Citizenship in the United States?" en Socialist Review, no 22 , 1992, pp. 45-65.

8 Este modelo cuyo máximo exponente es Marshall es lo que los autores Kymlicka y Norman han denominado la "ortodoxia de posguerra". Will Kymlicka y Wayne Norman, "El retorno del ciudadano. Una revisión de la producción reciente en teoría de la ciudadanía" en Ágora, no 7 , 1997, pp. $43-71$.

9 MAIR, Peter, Gobernando el vacío. La banalización de la democracia occidental, Alianza Editorial, Madrid, 2015. 
Este modelo, presente tanto a nivel nacional como supranacional ${ }^{10}$, viene de la mano de una serie de nuevos planteamientos que pretenden transformar el papel intervencionista del Estado a través de la llamada "gobernanza moderna", la cual deja a la administración pública estatal un rol de mero intermediario en las negociaciones entre corporaciones privadas y organizaciones de tipo sindical, que pasarían a ser las verdaderas encargadas de la elaboración de las políticas públicas ${ }^{11}$. Esta nueva opción, que coincide con lo que Colin Crouch denominaba "posdemocracia"12, se otorga el mérito de ser la única solución gubernativa factible ante la disfunción de los sistemas socialistas y la crisis -tanto económica como política- del modelo capitalista de la desregulación, la privatización y la no intervención estatal. Sin embargo, no es sino una "enésima reencarnación de la teoría civil liberal"13, en definitiva, una nueva "marca" detrás de la cual persiste el espíritu que busca normalizar la definitiva introducción del mercado en el proceso de toma de decisiones y de elaboración de políticas públicas.

El impacto de planteamientos como este se ha dirigido a apuntalar el proceso de desmantelamiento del Welfare State europeo y su sustitución por lo que Enrique Alonso denomina como un "Workfare State"14. En los Workfare State, la provisión de los derechos sociales deja de ser competencia del estado asistencialista y pasa a gestionarse a partir de una empresarialización de la oferta, es decir, de la concertación con el sector mercantil de la prestación de los servicios tradicionales. Supone la exigencia de una actividad laboral como "contrapartida de los beneficios aportados por políticas sociales"15. Esto no puede lograrse sin venir acompañado de una notable subordinación de los estados nacionales a las valoraciones y recomendaciones de los entes financieros internacionales.

Esto no es sino el fenómeno de mercantilización que vienen sufriendo desde las últimas décadas los modelos de provisión social, de modo que los sistemas sociales europeos van aproximándose paulatinamente a un régimen liberal al uso ${ }^{16}$, a través de privatizaciones y condicionando el propio suministro de servicios públicos al estatus sociolaboral del individuo, lo cual produce una relativa segmentación del sistema de aseguramiento en forma de la tradicional dicotomía público/privado. Además, este nuevo modelo asistencial genera una sociedad dual, haciendo que recurran a él las personas que no pueden costearse un aseguramiento privado -últimamente mucho más incentivado-, lo cual aumenta su carácter estigmatizador. De este modo, el Workfare supone también un cambio en las relaciones entre

\footnotetext{
${ }^{10}$ No olvidemos que esta corriente económica e ideológica es hegemónica tanto en las propias instituciones de la Unión Europea, como en los gobiernos nacionales de sus Estados miembros. Hasta la fecha, todos los gobiernos de países pertenecientes a la Unión Europea comulgan con la doctrina neoliberal y emulan sus prácticas, salvo en el caso de Grecia, donde se ha visto cómo no ha importado demasiado el signo del gobierno que hubiese en el país; prueba nuevamente de la pérdida de soberanía a favor de la entidad supranacional europea.

11 MAYNTZ, Renate, "El Estado y la sociedad civil en la gobernanza moderna" en Reforma y Democracia, no 21 , 2001, Caracas, pp. 1-8.

${ }^{12} \mathrm{CROUCH}$, Colin, Posdemocracia, Taurus, Madrid, 2004.

${ }^{13}$ ALONSO, Luis Enrique, "La crisis de la ciudadanía en Europa" en Revista Económica - Niterói, vol. 17, nº1 , 2015, p. 70.

14 Íbidem, pp. 71 y ss.

${ }^{15}$ KYMLICKA, Will y NORMAN, Wayne, op. cit., p. 46.

${ }^{16}$ Estas transiciones en cuanto a la forma y al tipo de modelo del Estado del Bienestar se entienden dentro de la clasificación realizada por Esping-Andersen, que se basaba fundamentalmente en el nivel de mercantilización/ desmercantilización de los sistemas de provisión social estatales. Gøsta Esping-Andersen, op. cit.
} 
los individuos con derechos sociales y el estado, cada vez con una menor labor garantista, y con el mercado como primer regulador ${ }^{17}$. Así, el estado debe suplir las necesidades de aquellos individuos que no pueden obtenerlas del ejercicio de esa competición, por lo que adopta un cariz vergonzante y, por ende, incrementa el fenómeno de estigmatización.

En este sentido, la mercantilización de nuestros modelos sociales no se limita meramente al hecho de trasladar al sector privado lo que antes era responsabilidad del estado - con la consiguiente descapitalización del sector público que esto provoca-, sino también la adaptación de estas dinámicas de tipo mercantil a los principios constituyentes de la sociedad y la propia mentalidad de los individuos. Vivimos, por tanto, la transformación de un Estado de Bienestar basado en las políticas sociales, productivas o de empleo, en un "Estado del rendimiento" 18 , basado fundamentalmente en políticas de rentabilidad tecnológica, financiera y monetaria.

Especial papel juega en todo este proceso de desmantelamiento de los Estados del Bienestar europeos y de mercantilización de los esquemas sociales la Unión Europea, sede de donde emanan las políticas de austeridad que los gobiernos nacionales deben adoptar de forma preceptiva en sus países. Se puede observar cómo, desde la implantación del sistema de moneda única, la Unión Europea viene actuando más como una agencia monetaria disciplinaria que como un ente defensor de las garantías colectivas de la sociedad. El desarrollo de Planes de Estabilidad imponen a sus miembros medidas antiinflacionarias y restrictivas -en contra de las fluctuaciones económicas naturales de los propios ciclos del capitalismo y que lógicamente no pueden ser manejadas y paliadas por devaluaciones de la moneda-, al mismo tiempo que se exigen estrictas cifras de deuda, lo que supone para los estados miembros la implementación de paquetes de medidas firmados en Bruselas y que se traducen a nivel nacional en recortes en los sectores pilares del Estado del Bienestar, como son la educación y la sanidad.

Todo ello ha provocado que las instituciones comunitarias sean vistas actualmente con mayor escepticismo que en toda su historia. Para muchas personas, la Unión Europea ha dejado de ser el principal vehículo modernizador y financiador del bienestar en todos sus aspectos, y ha pasado a ser el más feroz guardián de la doctrina neoliberal y de la austeridad presupuestaria, lo que ha generado numerosas corrientes de euroescepticismo -e incluso eurofobia- a lo largo de todo el continente y que se ha materializado recientemente y de forma abrupta en la salida del Reino Unido de este organismo.

En esta línea política de estricta austeridad que viene desarrollando la Unión Europea -contrario a lo que fue su espíritu originario-, la ciudadanía social conformada a lo largo de la segunda mitad del siglo XX se repliega hasta transformarse nuevamente en una suerte de ciudadanía liberal que hace referencia únicamente a las libertades políticas individuales, es decir, a los derechos civiles de Marshall. Así, los derechos económicos y sociales de bienestar y seguridad de la ciudadanía "plena" se han transformado en derechos económicos de propiedad y se inscriben en el marco global del mercado como regulador principal de estos

17 STANDING, Guy, El precariado. Una nueva clase social, Pasado y Presente, Barcelona, 2013.

${ }^{18}$ ALONSO, Luis Enrique, op. cit., p. 71. 
derechos. Asimismo, esto supone que los derechos sociales vuelvan a ser una condición disponible solo en función del estatus socioeconómico del individuo, con una consiguiente marcada segmentación social entre grupos ${ }^{19}$.

Al mismo tiempo, se abre una dinámica en el ámbito europeo por la cual además de darse un declive general de las políticas sociales, las que se mantienen se hacen más territoriales y están ligadas a unidades administrativas por debajo del estado nacional, en circunscripciones regionales o incluso locales. Esto supone para el estatus de ciudadanía una "disyuntiva paradójica"20, puesto que cuanto mayor es la globalización mediática y económica, más tiende a refugiarse en las propias comunidades locales la condición de ciudadanía social, de modo que el espacio local permanece como un espacio de resistencia, donde aún es posible establecer un mínimo pacto social. Así, comienza a gestarse un fenómeno por el cual parece considerarse que a pesar de que, como nos decía Beck ${ }^{21}$, la transversalidad de los riesgos actuales a los que se enfrentan los individuos provoca que estos no sean locales ni nacionales, sino globales, las soluciones a los mismos -o al menos el desarrollo de medidas paliativas contra ellos- sí pueden empezar por lo local22.

Algunas de estas iniciativas se reúnen bajo lo que se denomina como "municipalismo", que entiende que la democracia real comienza por lo próximo, lo local. Van desde la organización más pequeña, como puede ser un conjunto de vecinos y vecinas, hasta una plataforma ciudadana de ámbito municipal, que quieren incidir - aunque sea de forma mínima- sobre un problema que afecta a muchos, pero que comienzan por lo que les resulta más cercano y son capaces de desarrollar ese pacto social que les sirva de soporte colectivo.

Se trata, en cierta manera, de un proceso de regresión histórica, por la cual los individuos vuelven a encontrar en el municipio -o en espacios abarcables similares- una zona de confort donde tejer redes de solidaridad y donde incluso participar políticamente para el desarrollo de la propia comunidad, al estilo de las polis griegas. La fusión geográfica de la que hablaba Marshall en torno al concepto de ciudadanía se ve ahora contrarrestada, debido a que los individuos son capaces de adquirir los elementos que fundamentan su condición de ciudadanía social de una manera más clara en el espacio local que en el nacional.

Esto se circunscribe también en un contexto en el que el cambio en las relaciones entre el sistema económico y el político de las últimas décadas nos ha llevado hasta el cuestionamiento de nuestras formas de gobierno e incluso de la propia democracia como modelo óptimo ${ }^{23}$. Si bien se mantienen como principios cuasisagrados el sufragio universal,

19 DEL PINO, Eloísa y RUBIO LARA, Mo Josefa (eds.), Los Estados del Bienestar en la encrucijada: políticas sociales en perspectiva comparada, Tecnos, Madrid, 2015.

${ }^{20}$ ALONSO, Luis Enrique, op. cit., p. 74.

${ }^{21}$ BECK, Ulrich, op. cit., 1999.

${ }^{22}$ Esta tendencia "localista" opuesta a la inercia general de la hiperglobalización, puede llegar a generar tensiones por los límites que surgen en el ámbito de las competencias y que pueden incluso constituirse como un "muro" contra el que se chocan las iniciativas populares locales provocando cierta frustración política. Ejemplo de ello, son algunas situaciones que se han dado en el desarrollo de esta legislatura municipal en los denominados «ayuntamientos del cambio», cuyas iniciativas se han topado en varias ocasiones con la "realidad nacional", que incluso puede estar a su vez condicionada por la supranacional.

${ }^{23}$ En relación a esto cabe destacar las obras del politólogo Larry Diamond sobre el triunfo de la democracia como forma de gobierno en los años 70 y de la posterior regresión o "Democratic Rollback" que se viene produciendo 
la convocatoria electoral periódica y libre con un sistema competitivo de partidos y un Estado de Derecho que garantice las libertades del individuo - libertades negativas-, la desafección por parte de los ciudadanos hacia nuestros modelos de gobierno representativo hace que la crisis económica haya sacado a la luz una también profunda crisis política. La degradación de las democracias occidentales no es un fenómeno nuevo que se empiece a vislumbrar en la actualidad ${ }^{24}$, pero sí encuentra hoy unas críticas en cierto modo más generalizadas y que se fundamentan principalmente en torno a dos ejes: el de los derechos sociales -como ciudadanía social- y el de los derechos políticos de participación -como ciudadanía activa-.

Por un lado, y como comentábamos, se constata el fracaso de las democracias occidentales en su papel de garante de los derechos sociales de bienestar, seguridad y dignidad que se habían alcanzado en el siglo pasado y que habían constituido el relato central legitimador de las potencias europeas en la segunda posguerra. La destrucción de la ciudadanía social tal y como la conocíamos supone dejar al individuo en un estado de incertidumbre, que le lleva a adoptar posturas críticas con el sistema político en el que se inscribe e incluso hacia sistemas supranacionales como la Unión Europea, percibida como el ente desde donde se impone este "austericidio" a los Estados miembros.

Asimismo, y ante la falta de los elementos de carácter social que componían su condición ciudadana previa, estos individuos optan por actitudes de reclamo de nuevas formas de construcción de ese estatus de ciudadanía, haciendo uso de sus derechos políticos de participación. Es de aquí de donde proviene el segundo eje de críticas a nuestros modelos de democracia representativa, basados en el hecho de que la ciudadanía no dispone de mecanismos de control de la labor de los dirigentes ni tiene la posibilidad de interactuar en o con las instituciones del Estado. La falta de una posible accountability - rendición de cuentas, en castellano- de la clase política profesional hacia sus ciudadanos y la pérdida de transparencia que en ocasiones lleva a considerar la existencia de lo que Wolfe llamaba un "doble Estado" 25 ahonda en esa deficiencia de la democracia que no ha sabido cumplir sus promesas ${ }^{26}$.

Algunas alternativas buscan dar mayor densidad política a la participación ciudadana, lo cual entronca con la concepción republicana de ciudadanía - "ciudadanía activa"-, cuyo estatus no viene determinado por libertades negativas, sino positivas, en tanto en cuanto garantizan un vínculo en una práctica común, cuyo ejercicio es lo que permite a los ciudadanos

desde finales de la década de los 90. DIAMOND, Larry, "¿Puede el mundo entero ser democrático? Democracia, desarrollo y factores internacionales" en Revista Española de Ciencia Política, no 9 , 2003, pp. 9-38; DIAMOND, Larry, The Spirit of Democracy: The Struggle to build free societes throughout the world, Times Books, Henry Holt and Co, New York, 2008; DIAMOND, Larry, "The Democratic Rollback: the resurgence of the predatory state" en Foreign Affairs , 2008, U.S. Council of Foreign Relations.

${ }^{24}$ Referencia en este asunto es el célebre politólogo Samuel P. Huntington y sus análisis acerca de las democracias occidentales en el marco geopolítico global y de las Relaciones Internacionales. HUNTINGTON, Samuel P., The Third Wave. Democratization in the late twentieth century. University of Oklahoma Press, 1991; HUNTINGTON, Samuel P., The Clash of Civilizations and the remaking of world order, New York, Simon \& Schuster, 1996.

25 Uno de cara al público y otro de puertas adentro donde realmente se toman las decisiones. en WOLFE, Alan, The limits of legitimacy. Political contradictions of contemporary capitalism, The Free Press, New York, 1980.

${ }^{26}$ BOBBIO, Norberto, "Le promesse non mantenute della democrazia" en Mondoperaio, n5 , 1984. Traducción al español descargada de www.educ.ar. 
convertirse en sujetos políticamente responsables ${ }^{27}$.

Respecto a este nuevo ciclo de reclamaciones, cabe mencionar la relación que establecen con lo que Inglehart llamaba la era postmaterialista ${ }^{28}$. Según este politólogo, se establecía una brecha generacional por la cual se diferenciaba a la población nacida antes de 1945, cuyas preocupaciones principales tenían que ver con su realidad material -control de la inflación y garantía de seguridad-; y los nacidos después de esa fecha, cuando esos elementos ya estaban garantizados por el Estado del Bienestar, por lo que trasladaban sus demandas a otros ámbitos como la preservación del medio ambiente o un aumento de la participación de la ciudadanía en la vida política. La tesis de Inglehart funcionaba hasta la llegada de la crisis económica de 2008, cuando esa seguridad económica y social que estaba garantizada para las generaciones de la posguerra ya no lo está para las generaciones actuales. De esta manera, en las nuevas demandas de los movimientos sociales más contemporáneos se combinan estos dos tipos de cuestiones, las reclamaciones materialistas y las postmaterialistas, es decir, los derechos sociales y más y mejores derechos políticos.

\section{Ciudadanía indignada: nuevos modelos de ciudadanía. El caso de la PAH y el $15 \mathrm{M}$.}

Los movimientos sociales de protesta en España que vamos a tratar aquí surgen a raíz del estallido de la crisis económica global, cuando perciben que lo que antes constituían los derechos sociales de la ciudadanía han sido destruidos casi en su totalidad. A raíz de esto, observamos cómo se inicia un proceso de demandas articulado en dos ejes, ya mencionados arriba, cuyo fin es mantener o recuperar esos derechos sociales de bienestar, por medio de nuevas construcciones de la condición de ciudadanía o, más bien, adoptando elementos de corrientes paralelas ya existentes y de largo recorrido, como es el republicanismo y su propuesta de "ciudadanía activa".

Por tanto, estos movimientos sociales no solo buscan recuperar el elemento social del estatus de ciudadanía del que hablaba Marshall, sino hacerlo por medio de una reivindicación y profundización en el elemento político del mismo y a través de la participación. El sujeto político será ahora lo que se denomina como la "ciudadanía indignada". El común de este colectivo tan heterogéneo es el haber sido $-\mathrm{y}$ ser- objeto de las repercusiones negativas de la crisis ante la socialización de las pérdidas, así como de las políticas de austeridad provenientes de la Unión Europea - que contemplan como una realidad dada desde fuera que entra en conflicto con las realidades locales ${ }^{29}-$ y el hartazgo hacia las instituciones políticas y económicas, tanto del ámbito nacional como supranacional.

Por un lado, el nacimiento en 2009 de la Plataforma de Afectados por la Hipoteca - $\mathrm{PAH}-$, con unas reclamaciones más sectoriales emplazadas en el ámbito de la vivienda, responde a la situación precaria en la que colocó a millares de personas la burbuja inmobiliaria

${ }^{27}$ ARENDT, Hannah, Responsabilidad y juicio,Paidós, Barcelona, 2007; HABERMAS, Jürgen, "Tres modelos de democracia. Sobre el concepto de una política deliberativa" en Polis, no 10 , 2005.

28 INGLEHART, Ronald, The Silent Revolution: changing values and political styles among western publics. Princeton University Press, 1977.

${ }^{29}$ BARBEHÖN, Marlon, "Europeanisation as Discursive Process: Urban Constructions of Europe and the Local Implementation of EU Directives" en Journal of European Integration, DOI: 10.1080/07036337.2015.1110147, 17 de noviembre 2015. 
en España y su consiguiente cambio en el régimen de tenencia de la vivienda ${ }^{30}$. Los mecanismos de acción a los que recurre son fundamentalmente acciones de desobediencia civil, como protestas públicas, "escraches" -tradición procedente de los movimientos de protesta en Argentina - o parando desahucios. No obstante, cabe destacar de la PAH la existencia de toda una idiosincrasia que acompaña a esta desobediencia civil, que pretende reformar mentalidades y (re)construir colectividades y sentimientos de comunidad en nuestras sociedades individualizadas de hoy en día. Así, tal y como dicen Colau y Alemany, el primer objetivo de la PAH es generar un espacio de confianza y comunidad por medio de las reuniones presenciales, que les brinden la oportunidad de expresarse y compartir con otras personas su experiencia. Construir este espacio y poner en común las vivencias personales resulta vital para que los afectados se den cuenta por sí mismos de la dimensión colectiva de la problemática ${ }^{31}$.

Por tanto, en el seno de este colectivo uno de los propósitos fundamentales es el de desindividualizar, para sacar de lo común la voluntad y la fuerza de resistencia, para constituirse a sí misma como un espacio de soporte mutuo y solidaridad. En esta idea vemos el reflejo de un principio propio de la tradición teóricopolítica del republicanismo, con esa idea de res publica como "lo que es de todos", lo que a todos afecta y en lo que todos pueden participar. También se puede enmarcar dentro del republicanismo la iniciativa de crear una comunidad que no suponga la suma de los intereses de todos los individuos, sino que se constituya sobre un bien común, general y colectivo, que prime por encima de las personalidades, lo que guarda una enorme relación con ese ideal de la libertad de carácter republicano ${ }^{32}$.

Pero como decía, esta idea de construcción de comunidad no se queda ahí, sino que sirve para fundamentar la posterior actividad política que desempeñan dentro del marco de desobediencia civil, de forma que generar ese espacio de solidaridad responde al fin mayor de empoderar a los afectados y capacitarlos para la participación política, para ser ciudadanía activa, lo que constituye la parte visible del movimiento.

A su vez, esta idea de desindividualizar y de construcción de una comunidad como espacio de apoyo, confianza y solidaridad, guarda relación con esa disyuntiva paradójica de la que nos hablaba Enrique Alonso, y de esa regresión a lo local como punto de encuentro donde tejer redes de refuerzo de lo común y donde se puede crear un mínimo de pacto social. $\mathrm{Y}$ es que la PAH no se constituye como un colectivo centralizado, sino que cada territorio ha

\footnotetext{
${ }^{30}$ A raíz del ensalzamiento de la propiedad privada en aras de una estabilidad económica de las familias, se inició un proceso de estigmatización del alquiler como régimen de tenencia, a favor de la compra-venta de las viviendas. COLAO, Ada, y ALEMANY, Adriá, Vidas Hipotecadas. Angle Editorial, Barcelona, 2012, pp. 41 - 74.

31 Íbidem, p. 94.

32 En torno a esta cuestión de la libertad republicana como libertad colectiva trata el escritor y político Benjamin Constant en un famoso discurso pronunciado en 1819 en el Athénée Royal de París, titulado "Sobre la libertad de los antiguos comparada a la de los modernos". La llamada "libertad de los antiguos" era entendida como una forma más comunitaria, sometida siempre a la autoridad del conjunto y al bien general; mientras que la "libertad de los modernos" es una de carácter mucho más individualista - de ahí que escuchemos mucho más la expresión de libertades individuales que las libertades colectivas-. La primera supone una participación en la "cosa pública" y la subordinación de la libertad privada a la pública; mientras que la segunda, constituye fundamentalmente el derecho de cada uno a no estar sometido a nada más que a las leyes.
} 
ido creando la suya propia y funciona de forma autónoma, con las especificidades de cada localidad. Además, entroncando con los principios del "municipalismo", llevan a cabo una forma de activismo que es inmediata, sobre lo cercano, que "tal vez no cambie el sistema completo, pero conseguirá pequeñas victorias" ${ }^{\prime 33}$.

Ligado a este "municipalismo", a esta opción de lo local como espacio de lo común, se extiende un sentimiento de colectividad entre individuos en torno a otra percepción de "lo común", en este caso como pertenencia a lo que se llama comúnmente como «los de abajo» y que ha servido como signo de identidad para eso que denominábamos "ciudadanía indignada y que se aglutinó en el movimiento del 15 de mayo -o $15 \mathrm{M}-$.

Esta caracterización como "los de abajo" sin embargo, no debe ser equiparada a una división de clases y a la tradicional dicotomía burguesía/clase obrera dado que, como se ha comentado ya en este artículo, los límites entre unos estratos y otros en la sociedad de clases se difuminaron con el desarrollo del Estado del Bienestar. Al mismo tiempo, la destrucción de este Estado de Bienestar no parece estar conformando nuevamente esa división en clases calcando el modelo tradicional, lo que se demuestra con el hecho de que actualmente las personas carecen de autoconciencia en cuanto al estrato social clásico al que pertenecen, detrás de lo cual se esconden niveles reales de desigualdad entre unos grupos y otros ${ }^{34}$. Lo que sí se percibe es la autoubicación dentro de esa "gran brecha" de la que hablaba Stiglitz ${ }^{35}$, que separaba al 1\% de los más ricos del 99\% de la población restante, aquí, "los de abajo"36.

Esta nueva dicotomía arriba/abajo, ha conseguido robarle terreno al eje izquierda/ derecha en una nueva interpretación del tradicional cleavage capital-trabajo y en la era del fin de la ideología como instrumento de canalización de las demandas ciudadanas y de movilización política. La ideología, considerada aquí como conjunto de ideas y creencias, se muestra ineficaz en un momento de hegemonía global de un modelo económico, político y cultural en el que los problemas cotidianos parecen ser inmunes al cleavage izquierda/ derecha. La ideología funciona ahora como una "máquina expendedora"37, un mero atajo cognitivo.

El movimiento del 15M, por tanto, que engloba a toda esa ciudadanía indignada, es capaz de situarse en esa renovada fractura como "los de abajo" y hacer de ello una nueva

\footnotetext{
${ }^{33}$ ORDOÑEZ, Vicente, FEENSTRA, Ramón, y TORMEY, Simon, "Citizens against Austerity: a Comparative Reflection on Plataforma de Afectados por la Hipoteca (PAH) and Bündnis Zwangsräumung Verhindern (BZV)" en Araucaria. Revista Iberoamericana de Filosofía, Política y Humanidades, vol. 17, no 34, , 2015, p. 140.

${ }^{34}$ Un estudio realizado por Fernández-Albertos y Alexander Kuo muestra este error de autopercepción de la población española, de modo que los encuestados tienden a autoubicarse más cerca de los deciles propios de la clase media que lo que realmente están y solamente un $14 \%$ se sitúa con precisión en el decil que le corresponde. Esto ocurre tanto por parte de aquellos con unos ingresos más bajos como por aquellos que tienen unos ingresos mucho más elevados que los correspondientes a alguien de "clase media". ALBERTOS, José Fernández y KUO, Alexander, Relative income, information, and progressive taxation: evidence from a survey experiment. Sevilla, XI Congreso de la Asociación Española de Ciencia Política y de la Administración (AECPA), 2013.

35 SITGLITZ,Joseph, La gran brecha. Qué hacer con las sociedades desiguales,Taurus, Madrid, 2015.

${ }^{36}$ Incluso esta idea trasladada a eslogan con la fórmula "somos el $99 \%$ " fue uno de las señas más utilizadas en el ciclo de protestas del 15M, que habían copiado del movimiento Occupy Wall Street, y que reflejaba el elemento interclasista de la protesta de una mayoría empobrecida en oposición a una élite político-económica. www. movimiento15m.org, 27 de julio de 2013.

${ }^{37}$ BELL, Daniel, El fin de la ideología, Alianza Editorial, Madrid, 2015 1961, p. 85.
} 
seña de identidad común, desde la que avanzar en pos de recuperar el control democrático de la política y de la economía. Este objetivo solo es alcanzable partiendo de la participación política de esta ciudadanía indignada, transformándola en ciudadanía activa. Todo este proyecto supone un proceso democratizador en doble sentido ${ }^{38}$. Por un lado, exige al sistema político y a la clase política profesionalizada la no subordinación de la política a los mercados financieros ni a la orientación liberal-conservadora impulsada desde la Unión Europea y en su lugar, una mayor vinculación con los deseos e intereses de la sociedad; y por otro, señala las insuficiencias democráticas del sistema de representación electoral y aboga por una mayor transparencia y una participación activa de la ciudadanía, en definitiva, poner las instituciones al servicio de la ciudadanía, y no a la inversa ${ }^{39}$.

El 15M evidencia, por tanto, la ruptura del modelo tradicional de la democracia liberalrepresentativa como causa y, al mismo tiempo, consecuencia, de una crisis de representación. Los eslóganes "no nos representan" y "democracia real ya" son llamadas a un modelo diferente al gobierno representativo y a nuevas formas de hacer política. Por ello, desarrolla en mayor medida las demandas de carácter puramente político, reclamando una regeneración democrática con un mejorado modelo de representación, honestidad y transparencia de la clase política y promoviendo la participación activa de la ciudadanía. Estas demandas, que no hacen sino señalar un evidente déficit democrático, se entroncan en una serie de postulados también procedentes de la tradición teórico-política del republicanismo y sus exigencias de una democracia participativa o deliberativa, en la que además haya los suficientes mecanismos de rendición de cuentas o accountability, así como iniciativas de participación ciudadana, que permitan a la inmensa mayoría de la sociedad que no pertenece a la clase política profesional ser parte de las instituciones y del mismo proceso de toma de decisiones ${ }^{40}$.

Siguiendo el ideario del $15 \mathrm{M}$ y su objetivo de colocar a las instituciones al servicio de la ciudadanía, encontramos rastros del pensamiento republicano de Habermas, que afirmaba que el proceso político sirve para generar condiciones de posibilidad para los ciudadanos de adquirir estilos de una buena vida y que, asimismo, el estado debe velar por la garantía, no de los derechos privados de la ciudadanía, sino de sus derechos públicos y sus libertades políticas, que son libertades positivas ${ }^{41}$. Se trata por tanto de una defensa de los derechos de la ciudadanía, ya no sólo sociales, sino políticos, entendidos de una forma que no cabe en la tradición teórica liberal, donde los derechos son privados y las libertades son individuales, es decir, negativas, lo que se puede resumir en la fórmula "no hay nada que me impida hacer algo", en lugar de "no hay nada que me permita hacer algo". En la tradición republicana, en cambio, se entienden los derechos y las libertades como comunes, esto es, positivas, de tal modo que existe una garantía que permite al ciudadano desarrollar una actividad e incluso le incentiva.

Esta es la exigencia principal en cuanto a la participación política de la teoría republicana

\footnotetext{
${ }^{38}$ ANTÓN MORÓN, Antonio, Ciudadanía activa. Opciones sociopolíticas frente a la crisis sistémica, Ediciones Sequitur, Madrid, 2013, pp. 68 y ss.

${ }^{39}$ Esta idea se puede observar de forma sintética en el lema "No somos mercancías en manos de políticos y banqueros", utilizado por Democracia Real Ya!», uno de los grupos integrantes y más activos del 15M.

40 Manifiesto de "Democracia Real Ya!". www.democraciarealya.es

${ }^{41}$ HABERMAS, Jürgen, Facticidad y validez, Trotta, Madrid, 2008.
} 
y, a su vez, de los movimientos sociales actuales en España. Es cierto que no hay ninguna norma jurídica que prohíba tajantemente la participación ciudadana - a pesar del intento que supone la actual "Ley Mordaza"-, pero tampoco hay ningún mecanismo ni ninguna iniciativa que la fomente. Es de este déficit del que surgen los proyectos de lo que se conoce como «Gobierno Abierto», que lanzan cuestiones a la ciudadanía para incentivar su participación política y que de esta manera pueda participar en el proceso de toma de decisiones sobre asuntos que le competen y le afectan.

La participación constituye, de este modo, la "idea fuerza" que sustenta toda esta corriente de demandas políticas - que algunos llaman neorepublicanas ${ }^{42}-y$ es el elemento que marca una diferencia sustancial con otro tipo de corrientes teóricopolíticas y prácticas. Los reclamos de los movimientos en pro de una ciudadanía activa se fundamentan en el rechazo a la consideración de los ciudadanos simplemente como votantes, solo consultados y tenidos en cuenta cada cuatro años cuando se inicia el periodo electoral y que, básicamente, eligen lo que pueden, o lo que se les deja. La ciudadanía activa por la que abogan estos movimientos sociales actuales se detiene precisamente en no conformarse con el hecho de ser público pasivo a la orden de sus representantes, puesto que es en los ciudadanos en quienes recae verdaderamente la soberanía. Esto nos evidenciaban varios de los múltiples eslóganes que el 15M nos dejó, como "nuestros sueños no caben en vuestras urnas"43, lo que muestra una demanda de participación más allá de la meramente electoral.

Asimismo, tampoco vale conformarse con la adquisición nuevamente de los derechos sociales que antes garantizaba el Estado intervencionista del Bienestar, sino que buscan avanzar ahora en el carácter político de aquello que les convierte en ciudadanos. Para este estatus de ciudadano los derechos políticos de comunicación y participación política son el fundamento de todo. Si se quiere que la ciudadanía signifique no sólo un status de derechos prepolíticos y la paternalista garantía de los derechos sociales, se debe volver a un modelo de ciudadanía activa, de manera que todos los ciudadanos de la comunidad jurídica participen en la discusión y deliberación, la negociación, y los compromisos que establecen las normas de la convivencia social ${ }^{44}$.

Si bien es cierto que, a pesar de que los movimientos sociales actuales en España que estamos analizando aquí tienen tintes importantes de esa ciudadanía activa del republicanismo, no se ciñen estrictamente a los postulados de este cuerpo teórico. La importancia que se da a la participación en el republicanismo "clásico" - o "cívico", basado en Maquiavelo y Rousseaues "finalista", de forma que no se constituye como un medio para obtener o fiscalizar el poder de los representantes, sino que la participación es el fin en sí mismo, dando énfasis en el valor intrínseco que debe llevar, como virtud - la areté de los griegos- del ciudadano, que debe desarrollar sus deberes cívicos todos los días de su vida. Se trata de una ciudadanía basada, por tanto, más en deberes que en derechos, lo cual es algo radicalmente diferente al modo en el que están constituidas nuestras sociedades y nuestra condición ciudadana hoy en día.

\footnotetext{
42 DOMiNGo MORATALLA, Antonio, Hábitos de una ciudadanía activa. De la democracia escrita a la democracia vivida, Fundación Emmanuel Mounier, Madrid, 2007.

43 www.movimiento15m.org, 27 de julio de 2013.

${ }^{44}$ BENÉITEZ ROMERO, Benita, La ciudadanía en la teoría política contemporánea: modelos propuestos y su debate, Universidad Complutense de Madrid, Tesis Doctoral, Madrid, p. 291.
} 
Así, los reclamos de la PAH y el 15M dan una respuesta alternativa, tal vez a medio camino, más próxima a la que ha desarrollado tradicionalmente la izquierda en torno a la democracia participativa, otorgando a los ciudadanos más poder por medio de la democratización del Estado de Bienestar y por medio de la dispersión del poder estatal en una serie de instituciones democráticas locales o regionales ${ }^{45}$, pero que deja abierta la cuestión de la responsabilidad del "ciudadano activo".

\section{Conclusiones}

Identificamos el desarrollo del Estado de Bienestar desde el final de la Segunda Guerra Mundial como el momento de adquisición de los derechos sociales de Marshall y de la constitución, así, de lo que se conocería como "ciudadanía social", que identificaría y englobaría a una parte importante de la población de las sociedades occidentales industrializadas. Los derechos de seguridad y bienestar, garantizados por el estado asistencialista o intervencionista, serían los elementos que fundamentarían y completarían esta condición de "ciudadanía".

A pesar de que la tesis de Marshall ha sido repetidamente contestada y tachada de realizar una errónea visión de los derechos y/o por constituirse como una falacia universalista, nos servimos de ella por revelar una evolución innegable de la adquisición de los derechos y considerar que la ciudadanía es algo más que una circunscripción nacional y una identificación con un pueblo, lengua, cultura y una ley común; sino que la identifica con la adopción de una serie de derechos civiles, políticos y también sociales. La afirmación de estos derechos - privados- sociales como propios e inherentes al estatus de ciudadanía, son los que hacen su tesis reseñable y que pueda ser utilizada como marco para desarrollar la idea que aquí se presenta de una revisión de la "ciudadanía" en la actualidad. Si esos derechos sociales de Marshall, adquiridos por una notable parte de las sociedades occidentales gracias a los Estados del Bienestar, constituían un elemento fundamental y cerraban el carácter de la ciudadanía contemporánea, constituyéndola como "ciudadanía social", es lógico considerar que el proceso de desintegración del modelo de Bienestar provoque la propia ruptura de ese modelo ciudadano y la reacción hacia la formulación de uno nuevo.

En la actualidad, hemos sido testigos del desmantelamiento del Estado de Bienestar $y$, en general, del rol intervencionista del estado como consecuencia de diversos factores: por un lado, el proceso de integración europea que resta soberanía a los Estados, garantes de esos derechos sociales, a lo que se suma la expansión de la doctrina neoliberal -también desde la misma Unión Europea- y últimamente, del estallido de la crisis económica en 2008. La crisis, por tanto, no es el causante de la destrucción de la "ciudadanía social", sino tan solo el culmen de un proceso que venía desarrollándose desde la década de los ochenta con el auge del neoliberalismo protagonizado en Europa por Margaret Thatcher y que poco a poco, ha ido eliminando todo rastro de esos derechos sociales que fundamentaban dicha noción de ciudadanía por medio de la mercantilización de nuestras sociedades.

En el centro de este proceso se encuentra la Unión Europea que, olvidando sus principios originarios, confecciona y envía paquetes de medidas de corte neoliberal y conservador a los diferentes estados miembros para que allí se implementen, condenando a

${ }^{45}$ KYMLICKA, Will y NORMAN, Wayne, op. cit., p. 49. 
los ciudadanos a lo que se ha denominado como el "austericidio". Con sus políticas, cuestiona el significado de la ciudadanía social que tenía vigencia en Europa a partir de la posguerra. Esto, sumado a sus carencias democráticas, provoca que la Unión Europea se enfrente ahora a lo que, probablemente, sea el momento más difícil desde su nacimiento, con el creciente euroescepticismo que recorre el continente y que ha llegado a consagrarse con el Brexit. Se abre ahora para todos un debate intenso sobre si la vía a tomar es promover una mayor integración en el seno de la comunidad y una armonización y unificación real de los aspectos que continúan haciendo a los miembros de la Unión Europea desiguales; o por otro lado, si aceptar la derrota del proyecto europeísta.

Todo este clima desalentador en el ámbito de lo económico se traslada al campo de lo político e incluso se empieza a cuestionar el modelo democrático y de gobierno representativo en las naciones occidentales. La desafección ciudadana reina en Europa, tal vez de forma más acentuada en el caso de España donde sufrimos además una gran corrupción por parte de la clase política profesional. Esto genera una serie de críticas por parte de los movimientos sociales que giran en torno a dos ejes: el de recuperar los derechos sociales que un día fueron garantías, y el de aumentar los derechos políticos de los ciudadanos, en clave de apertura de nuevas vías para canalizar la participación política, transparencia y rendición de cuentas, de forma que se renueve y se dé sentido al acuerdo entre gobernantes y gobernados.

A su vez, y como consecuencia de la vulnerabilidad que se experimenta ante el funcionamiento de los procesos macroeconómicos y los poderes supranacionales que restringen o incluso dirigen a los gobiernos nacionales, se ha comenzado a producir un proceso de regresión histórica en forma de "vuelta a lo local" como zona de confort y como espacio donde establecer unos mínimos de pacto social, con redes de solidaridad y sentimientos de comunidad.

Todos estos elementos podemos verlos en el pensamiento de los movimientos sociales que hemos tratado aquí. Tanto la PAH como el 15M, ven cómo el elemento que antes constituía el fundamento de su ciudadanía, la "ciudadanía social" se ha destruido, por lo que abogan ahora por constituirse a partir de una nueva noción de ciudadanía: la "ciudadanía activa" de tradición republicana. De esta manera, se da una mayor relevancia al carácter político de la ciudadanía, en forma de acción, no quedándose solamente en la adquisición de nuevo de los derechos sociales de bienestar. En el nuevo modelo de ciudadanía activa que adoptan estos movimientos sociales, se pretende que todos los ciudadanos de la comunidad jurídica que lo deseen puedan tener la posibilidad de participar en la discusión y deliberación, la negociación, y los compromisos que establecen las normas de la convivencia social.

La participación, como praxis de lo político, se convierte, por tanto, en el eje común de las exigencias de los principales movimientos sociales españoles críticos con el sistema político y económico en el que estamos inmersos. Participación política no solo en el mínimo espacio que nos deja el modelo electoral, sino también como resistencia, o incluso en ocasiones como desobediencia, y que debe tener su reflejo y su repercusión en las propias instituciones, haciéndolas más dependientes de la sociedad civil de la que procede su poder y a la que debe rendir cuentas de su actuación por medio de instrumentos de transparencia y auditoría. 


\section{Bibliografía}

ANTÓN MORÓN, A., Ciudadanía activa. Opciones sociopolíticas frente a la crisis sistémica. Madrid, Ediciones Sequitur, 2013.

ARENDT, H., Responsabilidad y juicio. Barcelona Paidós, 2007.

BARBEHÖN, M., "Europeanisation as Discursive Process: Urban Constructions of Europe and the Local Implementation of EU Directives" en Journal of European Integration, nov. 2015.

BECK, U., La sociedad del riesgo global. Madrid, Editorial Siglo XXI, 1999.

BELL, D., El fin de la ideología. Madrid, Alianza Editorial, 2015 (1961).

BENÉITEZ ROMERO, B., La ciudadanía en la teoría política contemporánea: modelos propuestos y su debate. Madrid, Universidad Complutense de Madrid, Tesis Doctoral, 2004.

BOBBIO, N., "Le promesse non mantenute della democrazia" en Mondoperaio, n5 (1984. Traducción al español descargada de www.educ.ar.

CHALFOUN BLANCO, M., Bases para una ciudadanía activa en la Unión Europea: aprendizaje permanente y nuevas tecnologías, (1992-2010). Tesis doctoral, Universidad Complutense de Madrid, 2012.

COLAU, A., y ALEMANY, A., Vidas hipotecadas. Angle Editorial, Barcelona, 2012.

CROUCH, C., Posdemocracia. Madrid, Taurus, 2004.

DEL PINO, E. y RUBIO M.J. (eds.), Los Estados del Bienestar en la encrucijada: políticas sociales en perspectiva comparada. Madrid, Tecnos, 2015.

DIAMOND, L., "¿Puede el mundo entero ser democrático? Democracia, desarrollo y factores internacionales" en Revista Española de Ciencia Política, no 9 , 2003, pp. 9-38.

DIAMOND, L., The Spirit of Democracy: The Struggle to build free societes throughout the world. New York, Times Books, Henry Holt and Co, 2008.

DIAMOND, L., "The Democratic Rollback: the resurgence of the predatory state" en Foreign Affairs , 2008 , U.S. Council of Foreign Relations.

DOMINGO MORATALLA, A., Hábitos de una ciudadanía activa. De la democracia escrita a la democracia vivida. Madrid, Fundación Emmanuel Mounier, 2007.

ENRIQUE ALONSO, L., "La crisis de la ciudadanía en Europa" en Revista Econômica - Niterói, vol.17, n01 (2015, pp. 69-85.

ESPING-ANDERSEN, G.: Los tres mundos del Estado de Bienestar. Valencia: Alfons el Magnànim: Institució valenciana d'estudis i investigació, 1993.

FERNÁNDEZ-ALBERTOS, J. y KUO, A., Relative income, information, and progressive taxation: evidence from a survey experiment. Sevilla, XI Congreso de la Asociación Española de Ciencia Política y de la Administración (AECPA), 2013.

FRASER, N. y GORDON, L., "Contract versus Charity: Why is there no social citizenship in the United States?" en Socialist Review, no 22 , 1992, pp. 45-65.

HABERMAS, J., "Tres modelos de democracia. Sobre el concepto de una política deliberativa" en Polis, no 10,2005

HABERMAS, J., Facticidad y validez. Madrid, Trotta, 2008.

HOBSBAWM, E., Historia del siglo XX. Barcelona, Crítica, 2012 (1994).

HUNTINGTON, S. P., The Third Wave. Democratization in the late twentieth century. University of Oklahoma Press, 1991.

HUNTINGTON, S. P., The Clash of Civilizations and the remaking of world order. New York, Simon \& Schuster, 1996.

INGLEHART, R., The Silent Revolution: changing values and political styles among western publics. Princeton University Press, 1977.

KYMLICKA, W. y NORMAN, W., "El retorno del ciudadano. Una revisión de la producción reciente en 
teoría de la ciudadanía" en Ágora, no 7 , 1997, pp. 43-71.

LLERA, F. (coord.), Desafección política y regeneración democrática en la España actual: diagnósticos y propuestas. Madrid, Centro de Estudios Políticos y Constitucionales, 2016.

MARSHALL, T.H., y BOTTOMORE, T., Ciudadanía y clase social. Madrid, Alianza Editorial, 1992 (1950).

MAYNTZ, R., "El Estado y la sociedad civil en la gobernanza moderna" en Reforma y Democracia, no 21 , 2001, Caracas, pp. 1-8.

Observatorio Metropolitano, La apuesta municipalista. La democracia empieza por lo cercano. Madrid, Traficantes de Sueños, 2014.

ORDÓÑEZ, V., FEENSTRA, R., y TORMEY, S., "Citizens against Austerity: a Comparative Reflection on Plataforma de Afectados por la Hipoteca (PAH) and Bündnis Zwangsräumung Verhindern (BZV)" en Araucaria. Revista Iberoamericana de Filosofía, Política y Humanidades, vol. 17, no 34, 2015, pp. 133-154.

STIGLITZ, J., La gran brecha. Qué hacer con las sociedades desiguales. Madrid, Taurus, 2015.

WOLFE, A., The limits of legitimacy. Political contradictions of contemporary capitalism. New York, The Free Press, 1980. 